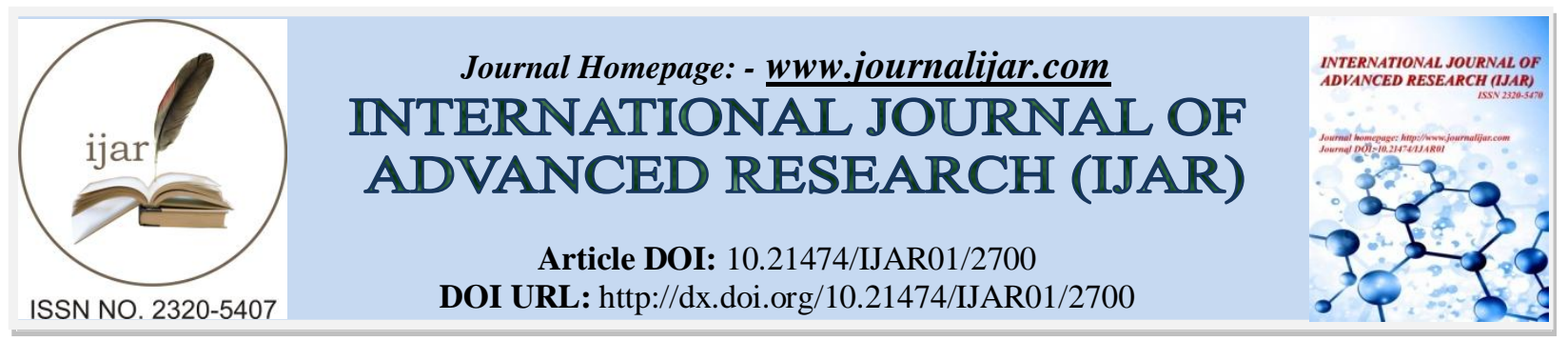

RESEARCH ARTICLE

\title{
A NOVEL L SHAPE MICROSTRIP PATCH ANTENNA.
}

Priyanka Jain $^{1}$, Vikas Maheshwari ${ }^{2}$ and Vandana Vikas Thakre ${ }^{2}$.

1. Deptt. of ECE, Amity School of Engg \& Technology, Amity University Madhya-Pradesh, Gwalior, M.P., INDIA.

2. Deptt of ECE, Madhav Institute of Technology and Science, Gwalior, M.P., INDIA.

\section{Manuscript Info}

\section{Manuscript History}

Received: 31 October 2016

Final Accepted: 01 December 2016

Published: December 2016

\section{Key words:-}

microstrip patch antenna, L-shape, multi-band, band width, HFSS

\section{Abstract}

In this proposed design a Rectangular micro-strip patch antenna is present with cutting $\mathrm{L}$ shaped slots within the Rectangular patch which operate at four central frequencies $2.04,3.2,3.8,4.3 \mathrm{GHz}$ Which is a new multi-frequency microstrip antenna. By proposed antenna design and coaxial feeding at suitable place the resultant return loss, VSWR and bandwidth will be find out. For the propose microstrip antenna we have use FR-4 substrate which contain permittivity of 4.4 and thickness 1.5 , loss tangent is 0.02 . HFSS simulation software is used for designing and analysis. With slotted patch antenna and coaxial feeding at appropriate location better return loss, VSWR bandwidth and multiband performance will be obtained.

Copy Right, IJAR, 2016,. All rights reserved.

\section{Introduction:-}

In recent instance the requirement for the multi mode antenna is demanded for person to person communication network which have been rising. The growing amount of mobile services incorporated into particular telecommunication system which has made multiband function an important characteristic of mobile phone antennas [1]. In current years, the dual-band or multi-band antennas contain a huge awareness for application towards multimode communication systems [2]. It is finely known that standard of microstrip patch antennas are smart explanation of lot of wireless communication which demand due to their low-priced, average, comfortable, and easy-to-manufacture structural design [3]. On the other hand, the bandwidth of the main configuration in a lot of application is not enough to wrap up the needed functioning frequency range.

The patch antennas typically have narrow bandwidth and regarding the bandwidth enhancement several techniques have been proposed, including the use of an impedance matching network, the use of multiple resonators, thick substrate, planar inverted F antenna, the shorted L-probe or U-slot antennas [4]. While a microstrip patch antenna is overloaded by reactive element such as slot, stub or shorting pin, it give tunable or multi frequency antenna features. For the most part a well-liked method for obtain multi-frequency behaviour is to introduce the slots lying on a single patch [5].

In this paper, a multiband L-shape microstrip patch antenna is proposed. The modified multiband L-shape microstrip patch antenna shows the ability to create multi-bands at different frequencies. The multiband behaviour of the modified L-shape microstrip patch antenna is described in terms of the number of return losses. The radiation patterns of the measured modified L shape microstrip patch antenna clearly show the power radiated by an antenna at different frequencies [6]. 
The proposed design presents an approach of the rectangular patch with three L-type slot of different size, based with the commercial electromagnetic simulation tool, the FEM based software, HFSS by ANSOFT. Section II describes the antenna design and analysis for microstrip patch antenna. Simulations and results of antenna are projected in Section III. Conclusion is followed by the Section IV.

\section{Antenna design and analysis:-}

The proposed antenna construction is given away in Fig. 1. The rectangular microstrip patch of measurement $\mathrm{W} \times \mathrm{L}$ in print on the grounded substrate, which contain a relative permittivity $\varepsilon_{\mathrm{r}}$ and also consistent by width h, the dielectric material is theoreticaly nonmagnetic by means of permeability $\mu_{0}$. The L-shaped slot with two small Lshaped slots among measurement (L1, W1), (L2, W2), (L3, W3) is preset in a rectangular patch (see Figure 1), the L-shaped patch rectangular antenna characteristics multi-band behaviour. The patch is feed with coaxial probe $(50 \Omega)$ which is easy to formulate and have simulated radiation. In proposed feeding method, the coaxial connector with the inside conductor extend as of ground from end to end the substrate and is soldered to the radiating patch, whereas the external conductor extend from ground up towards substrate .

The propose mathematical design of the practical antenna is given below

a. Effective Dielectric Constant:

$\epsilon_{\text {reff }}=\frac{\epsilon_{\mathrm{r}}+1}{2}+\frac{\epsilon_{\mathrm{r}}-1}{2}\left[1+12 \frac{\mathrm{h}}{\mathrm{w}}\right]^{-0.5}$

b. Fringes Factor:

$\Delta \mathrm{L}=0.412 \mathrm{~h} \frac{\left(\epsilon_{\text {reff }}+0.3\right)\left(\frac{\mathrm{W}}{\mathrm{h}}+0.264\right)}{\left(\epsilon_{\text {reff }}-0.258\right)\left(\frac{\mathrm{W}}{\mathrm{h}}+0.8\right)}$

c. Calculation of Length:

$\mathrm{L}=\mathrm{L}_{\text {eff }}-2 \Delta \mathrm{L}$

$\mathrm{L}_{\mathrm{eff}}=\frac{\mathrm{c}}{2 \mathrm{f}_{\mathrm{r}} \sqrt{\epsilon_{\text {reff }}}}$

d. Calculation of Width:

$\mathrm{W}=\frac{\mathrm{c}}{2 \mathrm{f}_{\mathrm{r}} \sqrt{\frac{\epsilon_{\mathrm{r}}+1}{2}}}$

e. Calculation of Ground Plane Dimensions:

$\mathrm{L}_{\mathrm{g}}=\mathrm{L}+6 \mathrm{~h}, \mathrm{~W}_{\mathrm{g}}=\mathrm{W}+6 \mathrm{~h}$

Where $\mathrm{W}$ is width of patch and $\mathrm{h}$ isthe height of substrate, $\mathrm{L}$ is length of patch $\Delta \mathrm{L}$ is extension in length due to fringingeffect and $\mathrm{c}$ is speed of light in free space $f_{\mathrm{r}}$ is resonant frequency [5].

In this proposed design the computation of length and width are done by given formulas. The dimension of antenna is given by table 1 . As shown in the figure. 1 the patch has three types of $\mathrm{L}$ shaped slot their dimensions are also given in table1. We used 'FR4' material for substrate which has dielectric constant 4.4 and height for this material is 1.5. Figure. 2 shows the design of antenna in software.

\begin{tabular}{|l|l|l|l|l|l|l|l|l|l|l|l|l|l|l|}
\hline variable & $\mathrm{L}$ & $\mathrm{W}$ & $\mathrm{L} 1$ & $\mathrm{~L} 2$ & $\mathrm{~L} 3$ & $\mathrm{~W} 1$ & $\mathrm{~W} 2$ & $\mathrm{~W} 3$ & $\mathrm{C} 1$ & $\mathrm{C} 2$ & $\mathrm{C} 3$ & $\mathrm{C} 4$ & C5 & C6 \\
\hline value & 16 & 36 & 10 & 4 & 4 & 30 & 10 & 10 & 1 & 1 & 2 & 4 & 2 & 4 \\
\hline
\end{tabular}

Table 1:- Dimensions of the Microstrip Patch Antenna 


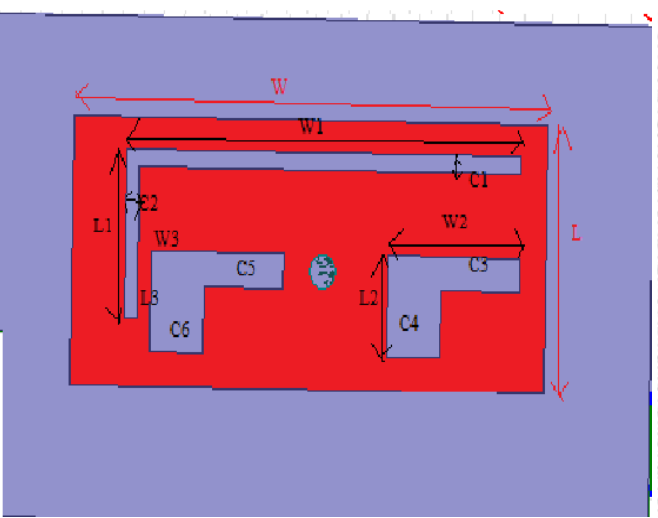

Fig: 1 Image of patch antenna

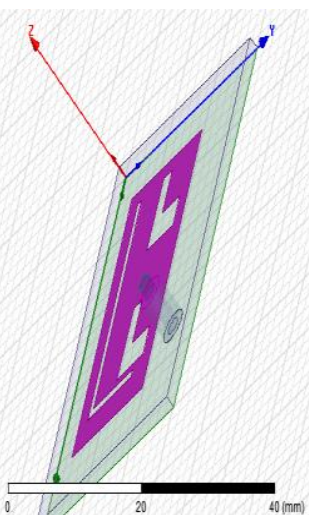

Fig: 2 Antenna design in software

\section{Simulation and result analysis:-}

HFSS simulation software is use for the simulation of micro-strip patch antenna. The deviation of return loss with frequency is shown in figure (3) of rectangular patch antenna through these L shaped slots. The proportion ratio of the Fourier transform of the incident pulse and the reflected signal is defined as the return loss which is an essential factor for antenna design. Figure (4) shows the VSWR graph for L shaped slotted rectangular patch antenna which is below than 2 for this multiband antenna. The VSWR indicate the difference among the transmission line and the antenna and for perfect matching the VSWR value must be close to unity. The return loss for the multiband microstrip patch antenna is shown in the figure (3) by which the four band is getting by this proposed design these are $(2.04,-15.14),(3.2,-20),(3.8,-16.6)(4.3,-16.9)$. The bandwidth is calculate at the frequency range where the return loss is just about below the $-10 \mathrm{~dB}$ and by the calculation it is given as $294 \mathrm{MHz}, 1773 \mathrm{MHz}, 311 \mathrm{MHz}$, 226MHz. Gain and directivity of antenna is shown in figure5 and 6. Figure (7) shows the simulated radiation pattern in 3D and the Smith chart is shown in figure (8) for the L shaped Slotted rectangular micro-strip patch antenna.

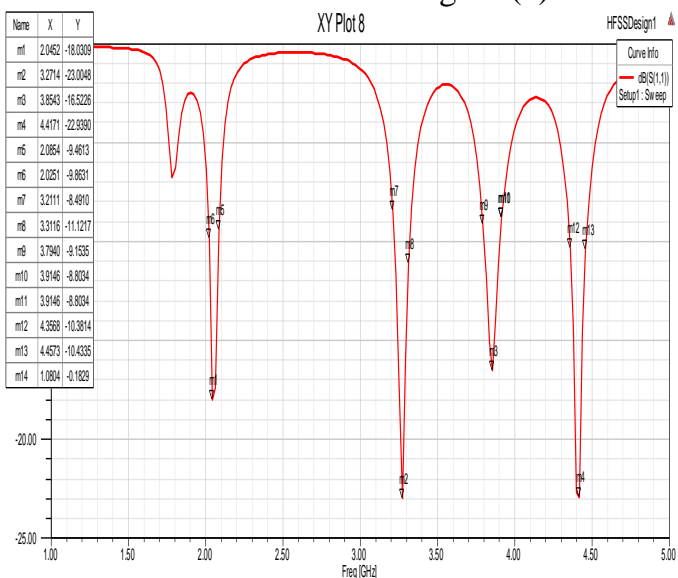

Fig: 3 Return Loss Of Antenna

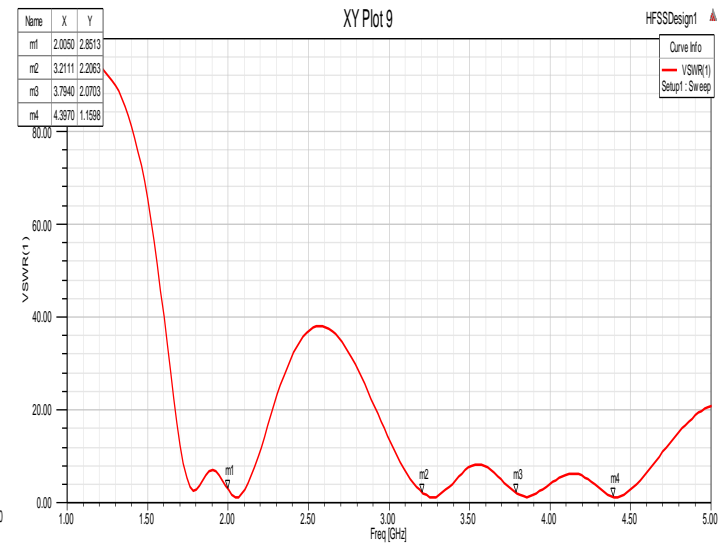

Fig: 4 VSWR Of Antenna

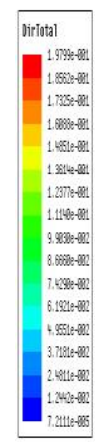

Fig: 5 Gain Of Antenna

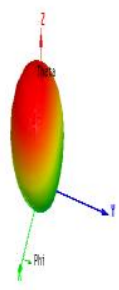

Fig: 6 Directivity Of Antenna 


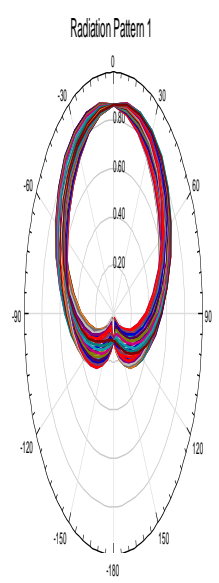

Fig: 7 Radiation pattern Of Antenna
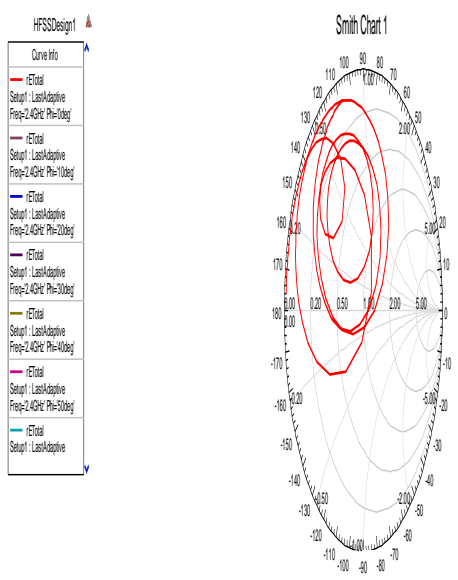

Fig: 8 Smith chart representation Of Antenna

\section{Conclusion:-}

The proposed L-shaped slot loaded rectangular microstrip patch structure can operate on more than two resonance frequencies and consequently this design can be used for multi band Operation. The properties of different physical parameter of antenna are investigated on the characteristics of this configuration. The present configuration could be capable of to meet up the requirement of different frequencies of wireless communication systems directly beside introducing slots of l-type in the dimension of the main antenna. Mathematical result show that in cooperation with the upper and lower resonant frequencies, the band widths relate to the dimension of the slot, by appropriately choosing the position of feed point and the slots multi bands can be achieved and controlled.

\section{Reference:-}

1. Kisangiri Michael, Andrzej A. Kucharski, "GENETIC ALGORITHM OPTIMIZATION FOR MULTIBAND PATCH ANTENNA DESIGN”, Proc. 'EuCAP 2006', Nice, France 6-10 November 2006 (ESA SP-626, October 2006)

2. Amel Boufrioua, "Dual Band Semi Circular Disk Patch Antenna Loaded With L-Shaped Slot", SAI, CDKP, ICAITA, NeCoM, SEAS, CMCA, ASUC, Signal - 2014 pp. 189-195, 2014.

3. Yejun He, Jiefeng Ao, Xiaorong Tang and Jie Yang,"The Optimum Design of PIFA Based on HFSS and Genetic Algorithm", 978-1-4244-6252-0/11/\$26.00 @2011 IEEE

4. Yong-Xin Guo, Kwai-Man Luk, Kai-Fong Lee, "A Quarter-Wave U-Shaped Patch Antenna With Two Unequal Arms for Wideband and Dual-Frequency Operation", IEEE Trans. on AP, vol. 50, No.8, pp. 1082-1087, August 2002

5. J. Malik and M. V. Kartikeyan, "Metamaterial Inspired Patch Antenna With L-Shape Slot Loaded Ground Plane For Dual Band (Wimax/Wlan) Applications", Progress In Electromagnetics Research Letters, Vol. 31, 35-43, 2012

6. Lavi Agarwal, Prateek Rastogi, "Multiband L Shape Microstrip Patch Antenna

7. for Wireless Communication", MIT International Journal of Electronics and Communication Engineering, Vol. 3, No. 2, August 2013, pp. 104-107 